\title{
POESIA ESPARSA, DESTINO ESPARSO: LEMINSKI EM SANTA CATARINA
}

\section{POESIÁA DISPERSA, DESTINO DISPERSO: LEMINSKI EN SANTA}

CATARINA

Rosana Clesar*

Jorge H. Wolff**

\author{
giovanitk@gmail.com \\ Graduanda em Letras-Português, DLLV, UFSC (Florianópolis, SC) \\ **giovanitk@gmail.com \\ Professor associado de Literatura Brasileira, DLLV-PPGLit, UFSC \\ (Florianópolis, SC). Observo que a existência deste texto se deve \\ exclusivamente à incansável pesquisa em arquivos de Rosana Clesa \\ que desenvolveu sua Iniciacão Científica (PIBIC) na UFSC entre agosto \\ de 2019 e agosto de 2020, sob minha orientação.
}

RESUMO: Na contramão dos itinerários de artistas brasileiros que historicamente se dirigem ao eixo Rio-São Paulo, o presente trabalho resgata a relacão do poeta Paulo Leminski (Curitiba, 1944-1989) com o estado de Santa Catarina, através de suas viitas para eventos litrailos, em tres momentos: em 1976, em sitas para eventos literáios, em tres momentos: em 1976, em Florianópolis e Blur tarinense. O trabalho lança mão de documentos localizados em acervos públicos e particulares e em hemerotecas nacionais que permaneciam pouco ou nada estudados. Foram recuperados depoimentos, reportagens, ensaios, fotografias e poemas inéditos em livro que podem oferecer novas percepções a respeito de sua obra. A partir deste material esparso são apresentadas relacões intelectuais também pouco exploradas, com destaque para nau, 1998).

PALAVRAS-CHAVE: Paulo Leminski; esparsos; Santa Catarina; Lindolf Bell; literatura menor.
RESUMEN: A diferencia de los itinerarios de artistas brasileños los cuales históricamente viajan hacia el eje Rio-São Paulo, el presente trabajo trata de rescatar la relación del poeta Paulo Leminski con la provincia de Santa Catarina desde algunas visitas para eventos literarios en tres fechas: y Blumenau y en el 1985 una vez más en la capital catarinense. E trabajo reúne documentos ubicados en archivos públicos y particulares y en las hemerotecas nacionales los cuales fueron poco o nada estudiados. Se han recuperado testimonios, reportajes, ensayos, fotografías y poemas inéditos en libro que pueden ofrecer nuevas percepciones respecto de su obra. Desde este material disperso se presentan relaciones intelectuales asimismo poco exploradas, destacándose la poesía corporal del poeta Lindolf Bell (Timbó, 1938 - Blumenau, 1998).

PALABRAS-CLAVE: Paulo Leminski; dispersos; Santa Catarina; Lindolf Bell; literatura menor. 
1. "A Palavra Destino", de $O$ código das águas (São Paulo: Global
Deixa vir a mim

a palavra destino.

Manhã de surpresas, lascívia e gema.

Acasos felizes, deslizes.

Ovo dentro da ave dentro do ovo.

Palavra folha e flor [...

Lindolf Bell

É inegável e compreensível que os itinerários de muitos artistas e escritores brasileiros tenham historicamente se concentrado no chamado eixo Rio-São Paulo. Gonçalves Dias, assim que volta de Coimbra, deixa sua cidade natal, São Luís do Maranhão, em busca da integração literária no Rio de Janeiro, numa capital imperial ainda não dominada pela figura de Machado de Assis. E chega gozando sucesso: em 1847 alcançara reconhecimento com a publicação de Primeiros Cantos. Já o poeta Cruz e Souza, que emigra da antiga Nossa Senhora do Desterro rumo ao centro do país em 1890, fixa-se definitivamente no Rio de Janeiro, onde publica Missal e Broquéis (1893), seu duplo-múltiplo delírio simbolista num Brasil "parnasiana Casa Grande”, no dizer de Paulo Leminski (1990a, p. 39). Quanto a João Cabral e Drummond, que apesar de terem Recife e Itabira como referências constantes em suas obras, não deixaram de transformar o Rio de Janeiro em palco de sua poesia, em diversos graus. São paulistas e paulista nos, mas ta mbém cariocas, os futurismos modernistas históricos, desvairados, pau-brasileiros e antropófagos: à exposição de Tarsila do Amaral no Rio em 1929 acorre toda a vanguarda do referido eixo, mais alguns detratores. Beats e concretos vagam pela Pauliceia do pós-guerra, vendo a geração Tropicália emigrar da Bahia. Torquato Neto deixa Teresina pela Guanabara. Lindolf Bell migra jovem de Timbó, no vale do Itajaí-Açu, em Santa Catarina, para São Paulo. Leminski deixa e não deixa Curitiba: como se sabe, viaja para poucos destinos, embora tenha vivido por um breve período no Rio e tenha enfrentado sobretudo a rodovia Régis Bittencourt (Curitiba-São Paulo) inúmeras vezes. É igualmente conhecida a sua ojeriza a aviões, em que ja mais teria posto os pés. A imaginação viajava longe, os roteiros eram exclusivamente terrestres.

Em todo caso, ensaia remos aqui o ca minho contrário, ou "des-encontrário", como ele talvez dissesse. Baixar para o sul e para longe do centro do país, talvez mais por proximidade e por inércia, mas certamente ta mbém por relações afetivas e intelectuais. O caminho "des-encontrá rio” em questão tinha como destino a região litorânea sul, Florianópolis e Blumenau, a não mais que 50 quilômetros em linha reta do mar, no estado de Santa Catarina, que naqueles tempos ditatoriais e logo 
2. Sabemos que houve ao menos uma quarta visita "oficial" de Leminski
a Santa Catarina, novamente a Blumenau e novamente em 1985 , cujos registros deverão ser buscados presencialmente em ornal daquela cidade a partir do momento em que isso voltar a ser possivel, com o fim da atual pandemia redemocratizantes não deixou de tentar mostrar ao país a sua face culturalmente desenvolvida e mesmo antifascista. Mas os costumeiros pontos de passagem meramente turística transformam-se neste estudo em destino final de um poeta nascido em Curitiba, cuja relação com escritores, artistas e jornalistas de Floria nópolis e de Blumenau, salvo engano, nunca foi abordada de modo mais detido. Precisamente, vamos nos desviar do eixo Rio-São Paulo para, junto com "o bandido que sabia latim", baixar nas duas cidades: Blumenau e Florianópolis, duas visitas num curto espaço de tempo, em 1976, e novamente, em Florianópolis, em 1985, tornadas visíveis a través de textos e imagens perdidas em a rquivos (fotos, notas, artigos de jornal e manuscritos) $)^{2}$. Em se tratando de "literatura menor", no caso de Leminski, em contraposição às altas literaturas e aos realismos de seu tempo, vamos considerar de saída, que "tudo é político" e que tudo nela ganha um "valor coletivo", nos termos de Deleuze e Guattari (1977, p. 39-40). Referimo-nos à noção de convívio, como poderia se referir a ela um tropicalista ou pós-tropicalista: à experiência comunitária, ao estar e viver juntos nos moldes a nárquicos da contracultura dos anos $70 \mathrm{e}$ arredores, assim como buscamos esse Leminski catarineta e minoritário a partir de suas viagens rumo ao sul, levando na mochila uma política e uma poética radicalmente inconformistas, e é nesse sentido que invocamos em seu nome o conceito de "literatura menor": por uma poesia concentrada e aguerrida, ferina e afetiva, alcóolica e lúcida, política e polêmica, viva e coletiva, conforme os rastros de textos e imagens que apresentamos a seguir.

\section{LEMINSKI NO DESTERRO, 1976}

Já na primeira visita "oficial" de Leminski ao estado de Santa Catarina, em 1976, como convidado da I Semana Nacional de Poesia, realizada no tea tro Álva ro de Carvalho, no centro de Florianópolis, e que durou de 26 a 31 de julho, o poeta deixaria sua marca e alimentaria a sua lenda de Rimbaud tropical. Na mesa "Discussões sobre o caminho da poesia no Brasil", ao lado do a migo "Pé Vermelho", o escritor Domingos Pellegrini, Leminski dorme solenemente enquanto o então escritor engajado discursa. Ao despertar, sem ter a menor ideia do que Pellegrini falava, ataca-o instintiva e sintomaticamente, defendendo sem mais nem por que um de seus pais concretistas, Décio Pignatari, presente na mesa, sendo que Pellegrini tinha acabado justamente de elogiar a fala de Pignatari, que o antecedera. A história é contada pelo próprio autor de Minhas Lembranças de Leminski (PELLEGRINI, 2014, p. 50-51), recuperando as circunstâncias do evento:

Em a uditório com coordenação de Lindolf Bell, Décio Pignatari fala, enquanto Leminski, sentado ao lado de Alice, 
dorme abraçado a uma garrafa de conhaque, que mamou "por causa do frio”. Quando acorda, Pé Vermelho está comentando a palestra de Décio, elogiando, mas presume que só pode estar criticando ou refutando, e levanta de pulo e dedo em riste:

- A poesia concretista é arte refinada de vanguarda, vocês são a retaguarda aguada e requentada que não leva a nada! A revolução na arte se dá, antes de tudo, pela forma, como mostrou Maiakovski, e não só pelo cha mado conteúdo, que pode ser até reacionário se fica no quadradismo das estrofes e da métrica fazendo quadras como caixões funerários da poesia!

Enquanto isso, Alice lhe puxava a ponta da camisa, sussurrando, e enfim fala ndo tão alto que todos ouvem:

- Paulo, ele não estava falando mal do Décio, estava falando bem!

Quando percebe que se excedeu sem razão, Leminski senta, seguindo-se daqueles silêncios em que só os pigarros falam; depois, Pé Vermelho continua falando entre sussurros e risadas abafadas do público. Leminski fica amuado.

A passagem ta mbém é contada na versão de Leminski (1999, p. 23), encontrada em uma carta de 1976 a Régis Bonvicino:
Aconteceu uma coisa incrível comigo recentemente em florianópolis

quando daquele concurso de poesia/simpósio

do qual décio participou também

e quando passamos juntos 3 dias sem parar

mostrei meus poemas discursivos/verbais a ele e o décio

com certeiro dedo

apontou o provincianismo em que eu estava caindo aproveitei a oportunidade para ter uma crise

bebi horrores

entrei em pânico

mandei gente à merda em público

dei vexame na conferência do décio

Com exceção deste episódio recorrente, que o biógrafo Toninho Vaz (2005, p. 200) vai chamar de "teatro nonsense", o evento parece ter decorrido conforme o programado. Reunindo cerca de cem pessoas todas as noites, o encontro fazia parte, segundo o promotor da jornada, João Aderson Flores, Secretário da Educação, Saúde e Assistência Social de Florianópolis na época, "da política de difundir a cultura do estado, buscando inicia tivas várias, criando um clima propício para a discussão, o debate e a absorção de ideias novas" (Tribuna da Imprensa, 14-15 de agosto de 1976$)^{3}$, no que logrou
3. Matéria sem título publicada pela carioca Tribuna da Imprensa, que cobriu o evento. Disponíve em: http://memoria.bn.br/ DocReader/154083_03/24691. 
4. Há divergências quanto ao número de trabalhos inscritos. A reportagem da Tribuna da Imprensa afirma que 370 originas jornal Desterro, em sua ediçẫo de setembro de 1976, afirma que foram 365 , mas de qualquer forma o número é expressivo. considerável sucesso: para o I Concurso Nacional de Poesia de Florianópolis foram mais de 360 trabalhos origina is inscritos ${ }^{4}$, de várias partes do país, dos quais doze foram selecionados para o lançamento da Antologia I Semana Nacional de Poesia, tendo o primeiro lugar ficado com Antônio Barreto, a utor do livro Eletroencefalograma, e o segundo lugar com Luis de Martino Coronel, autor de Mundaréu. O próprio Domingos Pellegrini também integrou a antologia com Tempo de Estrela.

O ainda pouco conhecido autor de Catatau, que constituiu o júri do concurso ao lado dos calejados Gilberto Mendonça Teles e Carlos Nejar e dos igualmente jovens Lindolf Bell e Pedro Bertolino, dá para a Tribuna da Imprensa a sua própria percepção do evento, com a acidez concretista que lhe caracterizava à época, em entrevista a Maria Amélia Mello:

Acho essa movimentação ótima. Em Curitiba (onde moro) não haveria nem essa frequência, nem essa animação, nem essa agressividade do público. A de se estar vivo, não é? Curitiba é uma cidade morta, uma cidade de vampiros. Sobre o concurso dentro dos 26 quilos que recebi em casa para ler e julgar, deu pra encontrar uns 18 poetas.

Você diz com linguagem própria?
Hoje em dia é muito difícil você encontrar alguém com voz própria. E está cada vez mais difícil. Quando peguei aquela "pilha" de originais vindo do Brasil inteiro, imaginei que fosse encontrar o grande poeta. Mas realmente isso não ocorreu. Acho que esse veículo (o texto no papel) está esgotado. É como um cavalo cansado. Todos trabalhos apresentados usavam a palavra, exceto uns dois ou três que faziam incursões muito desajeitadas na área da imagem, do visual. Isso seria, em primeira instância, uma conquista para a poesia concreta e, em seguida, do poema processo. Considero o poema processo um afluente, assim como a poesia práxis. É uma diluição, digamos assim: sempre tem alguém que vende mais barato, faz um trabalho menos bem feito por preço mais baixo. (Tribuna da Imprensa, 14-15.09.1976)

Como é comum no Leminski dos idos de 1970, não falta o ataque a Dalton Trevisan, aqui sob a personificação do vampiro dentro da cidade morta, assim como ta mbém não é novidade o ataque à poesia discursiva e aos "afluentes" do concretismo, práxis e processo. Para outro convidado do evento, na mesma Tribuna da Imprensa, o poeta e crítico Gilberto Mendonça Teles (1936-2018), “esta manifestação realizada em Florianópolis tem sido uma das mais inquietas e uma das mais fraternas que tenho visto no Brasil", acrescentando o a ugúrio de que o evento não se encerrasse em sua primeira realização: “Acredito

EM TESE BELO HORIZONTE $\quad$ v. $26 \quad$ N. $3 \quad$ Set.-Dez. 2020 CLESAR; WOLFF. Poesia esparsa, destino esparso: Leminski em Santa [...] P. 153-171

Teoria, Crítica Literária, outras Artes e Mídias 
(espero mesmo) que se crie um processo. Quer dizer, se ele for repetido anualmente, trazendo intelectuais, gente interessada em poesia, haverá resultado positivo e maior participação nacional.” Na visão de outro membro do júri, Pedro Bertolino, "com essa promoção, vejo um meio de surgir daqui pelo menos um incentivo para novos encontros, novas realizações". E, como balanço geral desse estado de poesia que tem lugar então na ilha de Santa Catarina, ficam marcadas as palavras de um de seus maiores incentivadores, Lindolf Bell, em franco contraste com o discurso de Leminski em relação à poesia:

Acho que é a hora e a vez do retorno à oralidade. Sempre acreditei que o poema de vanguarda é aquele que tem uma significação a tuante, real dentro do que o cerca. Ta mbém sempre acreditei que o poema oral (ou oralizado) estaria mais próximo das origens da própria poesia. A volta ao oral, que vimos neste encontro, é uma manifestação muito legítima, muito esperada depois desses anos todos em que a poesia se viu, quase sempre, condicionada a processos puramente visuais. (Tribuna da Imprensa, 14-15.09.1976).

Quanto à conferência de Leminski na I Semana Nacional de Poesia, pode-se inferir, a partir da breve cobertura feita pelo Jornal de Santa Catarina - que sintomaticamente o chama de "poeta paulista" -, que o discurso adotado não fugiu da recorrente postura bajuladora dos concretistas, pelo menos até certo ponto da década de 70: ele teria falado com ardor, como sempre, em nome da poesia visual e a favor do novo em todos os seus aspectos, como se pode depreender da nota publicada no referido jornal (aliás, pessimamente escrita), recortada abaixo:

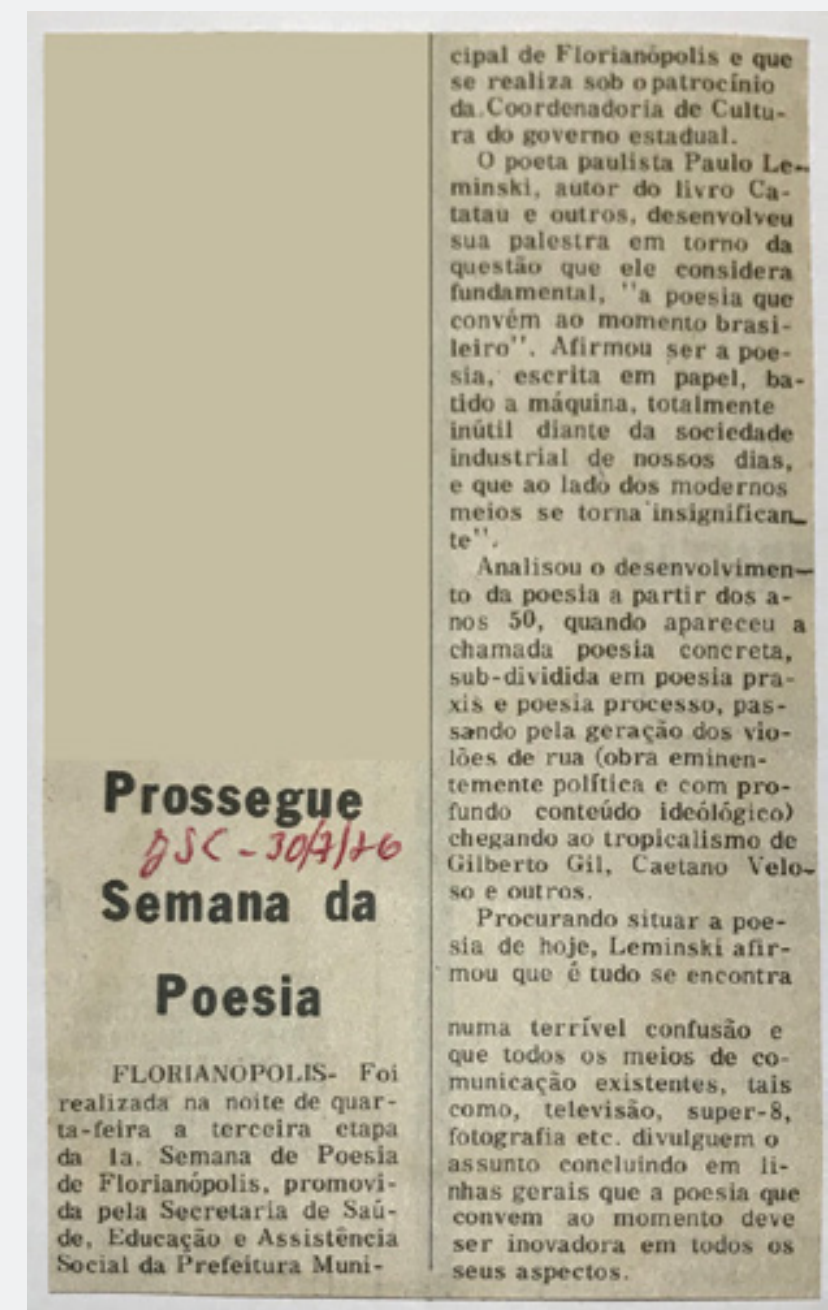

Figura 1: Nota do Jornal de Santa Catarina (Blumenau, 30.07.1976) Recorte cedido pelo Centro de Memória Lindolf Bell. 


\section{LEMINSKI EM BLUMENAU, 1976}

Quanto à segunda visita "oficial" a Santa Catarina, ela ocorreu em seguida, no mês de setembro, agora na cidade de Blumenau. Inaugurada em 27 de agosto de 1976 na galeria Açu-Açu e no Teatro Carlos Gomes, a VI (e última) Coletiva de Artes Plásticas Barriga-Verde, organizada por Bell, alinhava-se às mesmas pretensões da I Semana Nacional de Poesia: impulsionar a cultura no estado e criar um espírito artístico diverso e democrático, que permitisse o diálogo entre as mais variadas tendências artísticas da época no país, embora estivesse centrada nas artes visuais. Também propunha o fomento de uma produção artística a tuante nacionalmente e que se impusesse enquanto tal para além dos caminhos que levavam ao eixo Rio-São Paulo. Em entrevista à mesma Tribuna da Imprensa (Rio, 5-6.09.1976), Lindolf Bell - conhecido desde os anos 60 por sua "Catequese Poética" e pela ligação com poetas beats paulistanos como Cláudio Willer e Roberto Piva - explicita suas intenções com as Coletivas de Artes, que se davam de acordo com o seu próprio projeto artístico:

A descentralização dos núcleos culturais no Brasil sempre me preocupou. São Paulo, Rio de Janeiro, Belo Horizonte, Recife, tudo isso já não basta. A arte e a cultura precisam ser nutridas com outros elementos. Blumenau me pareceu uma possibilidade de criar um desses núcleos descentralizados. Núcleo polarizador e irradiador de cultura.

É importante salientar que o estado de Sa nta Catarina, ou uma parte significativa de sua região nordeste, refletia em boa parte as circunstâncias culturais e históricas do estado do Paraná, de colonização preponderantemente germânica, mais identificada com Curitiba do que com Floria nópolis. Segundo um historiador da literatura local, o modernismo só chegaria na província catarinense "com o Grupo Sul dos fins da década de quarenta" (SACHET, 1981, p. 108-113), assim como ocorreria na província paranaense, com destaque para os 21 números da revista Joaquim, publicados entre 1946 e 48, manifestando uma permanente tensão entre a chamada Geração de 45 e a Semana de 22. É importante observar, nesse sentido, que essa mesma tensão se manifesta em Santa Catarina, segundo um artigo sobre o modernismo no estado:

O movimento modernista catarinense se vincula à expansão desse movimento da década de 40 , e, portanto, não cabe relacioná-lo diretamente com a Semana de Arte Moderna de 1922. O próprio Melo Filho ${ }^{5}$ observa que o movimento de 22 é restrito a alguns centros, enquanto o movimento da década de 40 é bem mais amplo e a tinge todo o país. (MALAGOLI DA SILVA, 2007, p. 41)
5. Osvaldo Ferreira de Melo Filho (1929-2011), advogado, professor e compositor de Florianopolis, objeto de estudo do artigo "Modernismo e história da literatura na década de 1950 em Florianópolis", de Héverton Malagoli da Silva (ver Bibliografia) 
6. Em "Sem sexo, necas de criação", Leminski (2011, p. 111-118) desenvolve a ideia de que quem dá o tom a Curitiba e o imigrante, que, místic mals nada, desenvolveu a poeta liga intimamente à reprosã

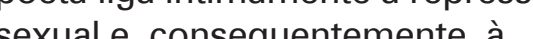
baixa produção cultural da cidade. Segundo Leminski, faltaria Curitiba um húmus da criativida popular: a presenca do elemento negro - que possibilitou o samba ga Tropicália. Assunto que ele desenvolveria em "Alegria da senzala, tristeza das Missões", um dos mais importantes textos de seus Ensaios e Anseios Crípticos.
Poder-se-ia dizer, portanto, que o Grupo Sul (Eglê Malheiros, Ody Fraga, Salim Miguel, Aníbal Nunes Pires e outros) esteve para Santa Cata rina assim como o grupo da revista Joaquim para o Paraná no imedia to pós-guerra. Sintomatica mente, Celestino Sachet (1981, p. 109-110), em sua documentação da literatura local, apresenta um a rgumento semelhante ao encontrado em um ensaio de Paulo Leminski, "Sem sexo, necas de criação" (Ensaios e Anseios Crípticos, 2011) em relação ao Paraná: o de que, em Santa Catarina, o "progresso econômico não se fez acompanhar do aumento da produção cultural" e de que faltaria "aquele cheiro de povo" - o "húmus" básico, segundo Leminski - para que a literatura da província ao sul fosse fecunda e de alguma maneira "típica", reconhecível. ${ }^{6}$ Nesse sentido, dentre as ressonâncias desse modernismo de 1940, com o papel de atualizar as artes de Santa Catarina em relação ao que vinha acontecendo nos grandes centros, se encontra, na década de 1970, a tentativa de afirmação nacional do estado enqua nto polo irradiador de cultura. Dessas ações fizeram parte os eventos a ntes mencionados, como a I Semana Nacional de Poesia e as Coletivas de Artes Plásticas Barriga-Verde, a mbas com participação ativa de Lindolf Bell, que se retira das grandes metrópoles, passando a residir novamente em Blumenau com a intenção tão louvável quanto quixotesca de descentralizar as artes brasileiras. É importante frisar aqui que Bell, para a posterior realização das Coletivas de Artes Plásticas, semeou o terreno antes - ao lado da escultora Elke Hering - com a inauguração da primeira galeria de artes do estado, em 1970, a Açu-Açu, ${ }^{7}$ antecedendo Floria nópolis nesse sentido, que vai conhecer a sua primeira galeria poucos anos depois, em 1973, o Studio A/2, de Beto Stodieck - jornalista que, segundo Fonseca (2008, p. 64) e conforme o vocabulário ca racterístico do desbunde ${ }^{8}$, vinha realizando "a transa total que Florianópolis há muito esperava”, e que trouxe à galeria e ao cenário da Ilha de Santa Catarina nomes como Os Mutantes, Gal Costa, Chacal e a turma da geração mimeógrafo, além de espetáculos com artistas catarinenses. A galeria Açu-Açu, assim como o Studio A/2, podem ser compreendidos, portanto, como "parte desta cruzada contra a falsa cultura" (FONSECA, 2008, p. 66), pela explosão de "novas cucas" com o advento da contracultura e dos novos coletivos artísticos, tendo Bell como seu representante em Blumenau e Stodieck na capital do estado. ${ }^{9}$

Durante o evento em Blumenau, Paulo Leminski, acompanhado por Alice Ruiz, a utografa o seu romance-ideia Catatau, publicado no a no anterior, ao lado dos quatro poetas engajados da Editora Cooperativa de Escritores, Domingos Pellegrini, Raimundo Caruso, Hamilton Faria e Reinoldo Atem, com quem mantinha
7. "No fundo do vale do Itajaí/Ali rastejo, festejo, / O coração colono /Na calma colina", escreve Bell em "Minifúndio", de $O$ código das águas. O nome da galeria é uma referência ao rio Itajaí-Açu, que corta Blumenau.

8. A propósito do "desbunde" ou de seu sinônimo, a "curtição", remetemos, por exemplo, aos artigos "Os abutres" e "Caetano Veloso enquanto superastro", de Silviano Santiago, em Uma literatura nos trópicos (1978).

9. "Muito blefe será desmistificado. Muitos dos considerados 'bons' pela 'crítica especializada' cairão por terra. E que na realidade, não passam de bons comerciantes lou [])" STODIECK Beto Jornal de Santa Catarina, 29.07.1973. “Who is Who nas artes de Santa Catarina" apud FONSECA, 2008, p. 66.
EM TESE BELO HORIZONTE $\quad$ v. $26 \quad$ N. $3 \quad$ SET.-DEz. 2020 CLESAR; WOLFF. Poesia esparsa, destino esparso: Leminski em Santa [...] $\quad$ P. 153-171 
Figura 2. Leminski e Alice na $6^{a}$ Coletiva de Artes Plásticas Barriga-Verde, em 1976. Jornal de Santa Catarina, 08.10.76. Coluna e Colunista não Centro de Méńria Ling cedida pelo

10. São inúmeras as polêmicas envolvendo Leminski e os poetas participantes, a exemplo, o texto "Poema para certa canção: um desafino", publicado em 16 de setembro de 1976, por Leminski, no Diário do Paraná. Disponível em: $<$ http://memoria.bn.br/
DocReader/761672/113655>.

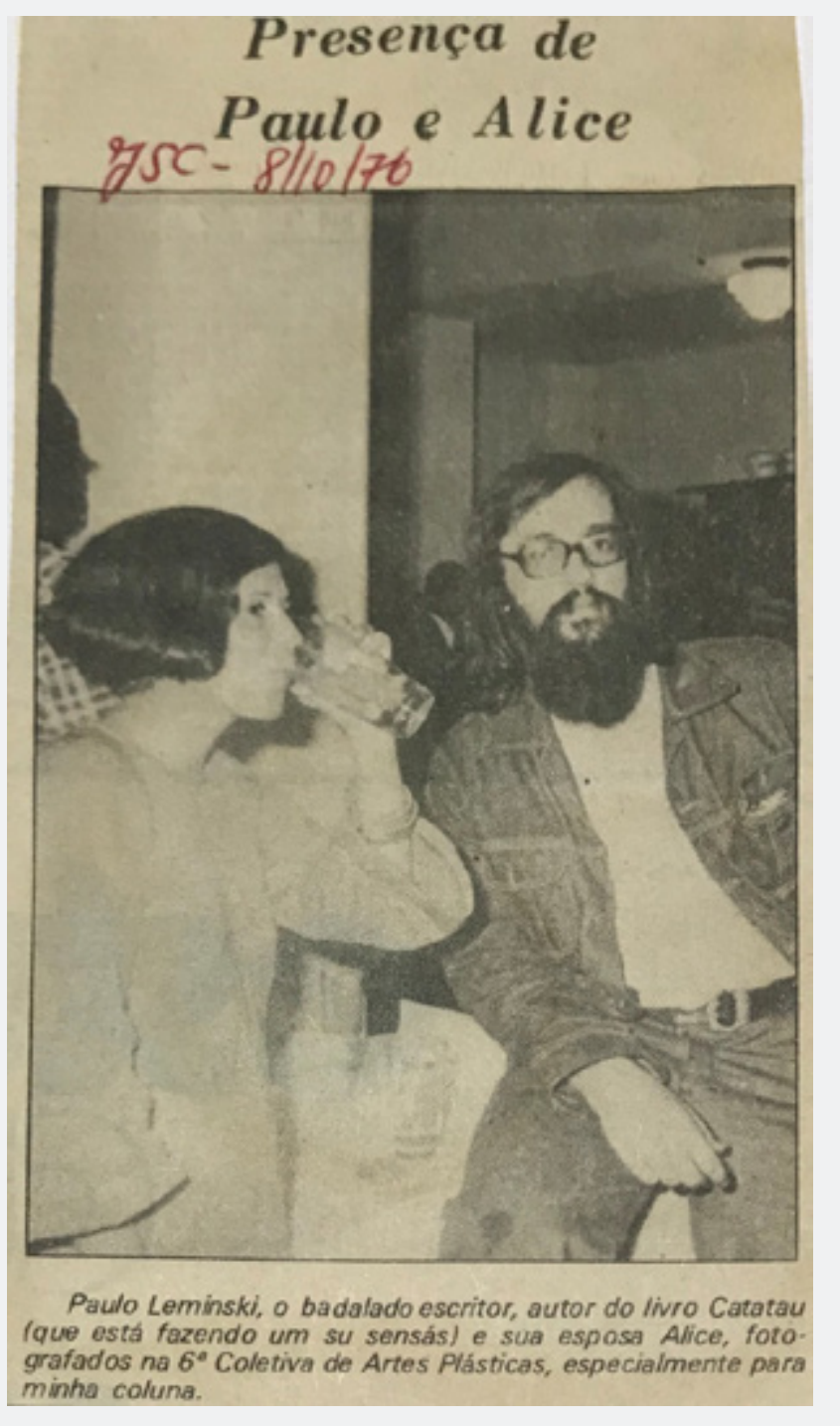

a mizade e polêmicas constantes. ${ }^{10}$ Com base nesse intercâmbio cultural e com vistas à divulgação das a rtes de Santa Catarina no cenário nacional, comemora-se que "começou em Santa Catarina um movimento polivalente da cultura, envolvendo todas as linguagens criativas, a cidade de Blumenau feita ponto de convergência e irradiação” (KELLERMANN apud SCHVARTZ, 2013, p. 53). Nesse contexto, Leminski - apesar de jovem, já conhecido agitador da cultura brasileira - aparece e funciona como estimulador e a ntena da raça para os jovens artistas e poetas sulistas, infundindo o que havia de mais novo, ousado e cria tivo no cená rio brasileiro em termos estéticos, ao mesmo tempo em que via ali se concretizar uma proposta que ta mbém buscava realizar em Curitiba. Como se sabe, foram inúmeros os eventos culturais em que se envolveu na "Culturitiba" natal, como com o grupo do Teatro Paiol, com a própria prefeitura da cidade e, ainda mais visceralmente, com os núcleos de cultura underground local, na tentativa de tornar a cidade um "polo cultural". Para dar apenas um exemplo, esses agitos foram estampados por Leminski no texto "Da Santos Andrade à Praça Osório (Curitiba ou a necessidade de inquietação)", publicado no Diário do Paraná no dia 6 de fevereiro de 1977.

Em entrevista para este trabalho, o cineasta e jornalista Eduardo Paredes, paranaense radicado em Santa Catarina que era o anfitrião de Leminski em Florianópolis e de quem havia sido colega no suplemento Anexo do Diário de Curitiba, analisa que os eventos jovens

EM TESE BELO HORIZONTE $\quad$ v. $26 \quad$ N. $3 \quad$ SET.-Dez. 2020 CLESAR; WOLFF. Poesia esparsa, destino esparso: Leminski em Santa [...] P. 153-171

Teoria, Crítica Literária, outras Artes e Mídias 
11. Ex-diretor do Museu da Imagem e do Som de Santa Catarina, Eduardo Paredes dirigiu, entre outros, os filmes Desterro (1991) e Novembrada (1998), duas importantes intervenções críticas no panorama historico e político do estado. Vale observar, ainda, que Paredes é irmão da jornalista Berenice Mendes, companheira de Leminski nos seus dois últimos anos de vida.

12. Em carta a Régis Bonvicino de 11 de agosto de 1978 , Leminski sugere que o amigo "mande brasa num negócio explicitamente político/poético", dando sugestões de títulos para um futuro trabalho do poeta paulista (que seria publicado no Folhetim da Folha de S. Paulo), entre os quais este: "A DITADURA ESVAZIOU A POESIA, VAMOS ENCHER" (LEMINSKI e BONVICINO, 1992, p. 102). No entanto, a noção de "vazio cultural" era polêmica e foi relativizada, por exemplo, por Heloísa Buarque de Hollanda em /mpressões de viagem. $C P C$, vanguarda e desbunde (1979). da época automaticamente se transformavam "num ato de resistência à ditadura militar, ao autorita rismo, àqueles anos de chumbo que foram anos pesados, anos trágicos da vida do povo brasileiro". ${ }^{11} \mathrm{O}$ que se dava, principalmente, pela criação de espaços alternativos, zonas de respiro, de liberdade de pensamento nas artes, o mais distantes possível do controle dos meios oficiais, marcados pela censura e pelo cerceamento da produção artística, que muitos denominavam, inclusive Leminski, de "vazio cultural". ${ }^{12}$ Pa redes lembra ta mbém que Leminski costumava participar, inclusive como jurado, dos festivais de cinema Super-8 de Curitiba, outra arma muito utilizada como forma de expansão das artes poéticas menores do início dos a nos 70.

\section{LEMINSKI NO DESTERRO, 1985}

A terceira passagem "oficial” de Leminski por Santa Catarina deu-se no mês de agosto de 1985, ou seja, em outro cenário político, quando o país tinha apenas saído da ditadura cívico-militar instalada em 1964, resultando numa grande intensificação dos debates e da produção cultural, tanto no aspecto intelectual quanto no mercadológico (a exemplo do boom editorial e fonográfico), tanto nas regiões centrais, quanto nas mais periféricas. O próprio a utor do best-seller Caprichos ef relaxos havia se tornado um dos protagonistas desse boom, com sua produtiva passagem pela editora Brasiliense e com a visibilidade que ganha como letrista da melhor MPB do momento. No plano das políticas públicas, observa-se que:

diante das oportunidades institucionais que caracterizam o período que antecede o final da ditadura, particularmente a partir de 1982, com as primeiras eleições diretas para os governos estaduais, mudanças nas políticas regionais propiciaram a criação de secretarias de Cultura, bem como de organizações voltadas a discussões de propostas e defesa de novas ideias nessa área. (FERRÓN e ARRUDA, 2017, p. 173)

Acompanhando os ares de mudança no cenário cultural brasileiro, ocorre precisa mente em 1982 o lançamento da I Bienal Nestlé de Litera tura Brasileira, tendo, ao todo, cinco edições, num período compreendido entre 1982 e 1991. Segundo consta no site oficial da empresa, tais eventos tinham "a finalidade de incentivar o surgimento de novos escritores no cenário literário nacional e fomentar a produção dos escritores contemporâneos", assim como ta mbém visou a "homenagear os grandes a utores já consagrados”. Dessas cinco edições da Bienal realizadas antes que se convertesse em Prêmio Nestlé de Literatura Brasileira, em 1993, Leminski participou da terceira, realizada em Florianópolis nesse agosto de 85,

EM TESE BELO HORIZONTE $\quad$ v. $26 \quad$ N. $3 \quad$ SET.-Dez. 2020 CLESAR; WOLFF. Poesia esparsa, destino esparso: Leminski em Santa [...] P. 153-171

Teoria, Crítica Literária, outras Artes e Mídias 
com o apoio da Universidade Federal de Santa Catarina, que sediou o evento.

O poeta Alcides Buss, na época professor de literatura na UFSC e um dos convidados da III Bienal Nestle de Literatura Brasileira, conta em seu livro Em nome da Poesia (2018) que as bienais Nestlé possuíam, como projeto, estimular a literatura brasileira e "por motivo da força que ganhava a poesia em toda a ilha de Santa Catarina, Floria nópolis foi escolhida para sediar o seminário" (BUSS, 2018, p. 128). Como na década anterior, a ilha e o estado buscavam reagir aos ventos das artes jovens nesse momento de reconfiguração intelectual e política da virada para os anos 80 , em direção à mundialização econômica e digital, tendo na figura de Buss, que foi diretor da editora da UFSC, um de seus entusiastas mais interessados: ele próprio promovia como poeta os "varais literários", que circularam pelo estado e mesmo para além dele, conforme inventariado por Sachet (1981). Registrou-se igualmente nesse período o chamado Movimento dos Artistas Independentes de Santa Catarina, integrado por escritores tão diversos como o jornalista e escritor Raimundo Caruso e o poeta e editor Cleber Teixeira. Amplo e generalizante em função do próprio ecletismo da categoria representada, seu manifesto bradava "pela dignidade e independência do artista frente ao poder econômico e político" e "pela dignidade e independência do artista e do trabalhador intelectual em Santa Catarina" (Travessia ${ }^{\circ} 3$, Florianópolis, PPGLitUFSC, p. 112-13), que contava com Silveira de Souza e Rodrigo de Haro entre seus escritores mais destacados, além do próprio Lindolf Bell e do vetera no Salim Miguel.

Com mais de quinhentos inscritos de todo o estado, a Bienal Nestlé realizada em Floria nópolis, nas dependências da ala C do Restaurante Universitário da UFSC, teve como um dos seus organizadores o escritor Ricardo Ramos, junto de outros veteranos como Ferreira Gullar e Gilberto Mendonça Telles, ao lado dos quais figuravam os jovens Raul Antelo (crítico e professor argentino radicado na ilha) e Carlos Damião (poeta e jornalista), além de Eglê Malheiros e Salim Miguel. Já, na mesa de debate do seminário "A Poesia Brasileira Hoje", figurara m, além de Leminski, Mário Quintana, Lindolf Bell, Alcides Buss, Bella Jozef, Osmar Pisani e Renata Pallottini. As falas dos escritores foram registradas em vídeo, mas as gravações infelizmente se perderam e, segundo Alcides Buss e Aldy Vergés Maingué, funcionário da Agecom (Agência de Comunicação da UFSC), não ficaram pistas delas. Buss, no entanto, confidencia em seu livro que, no momento da mesa, ocorrida durante toda a tarde do dia 29 de agosto, "Leminski discreta mente puxou do bolso uma uisqueira, 
sorvendo vários goles. Estava com a palavra. Dirigindose a Bell, no extremo oposto da mesa, disse que ele era Bell, o poeta mais bonito do Brasil. Todos riram, o a mbiente se descontraiu" (BUSS, 2018, p. 128). Conta ainda que, após a mesa, os poetas fora m levados pelo jornalista Laudelino Sardá a um hotel para a gravação de um documentário com Mário Quintana "a partir de perguntas ou colocações feitas pelos demais” (BUSS, 2018, p. 129), do qual tampouco restaram pistas.

Seguem algumas imagens do evento, gentilmente cedidas pela Agecom:
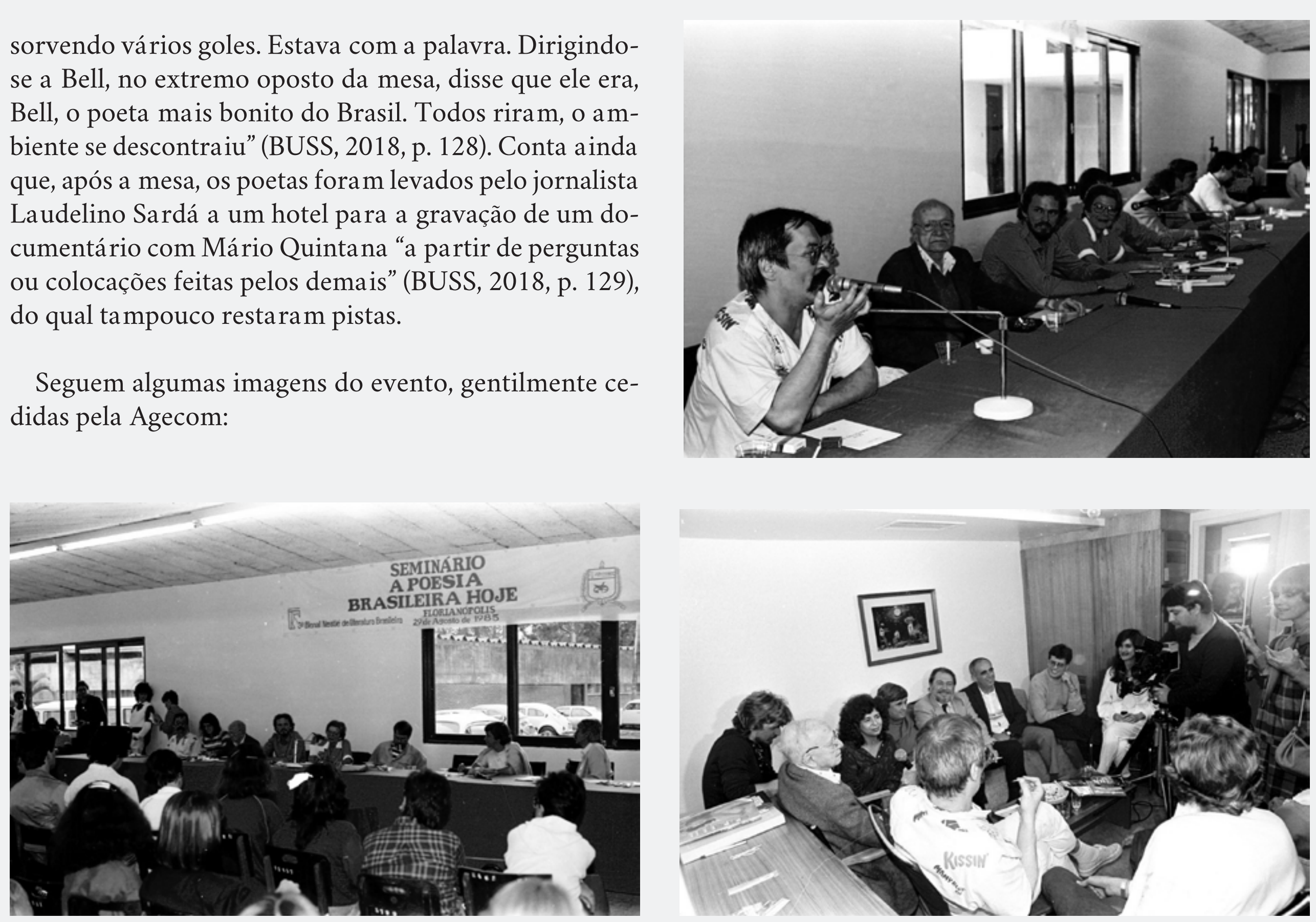

Figura 4. Mesa de debates do seminário "A Poesia Brasileira Hoje", em 1985. Da esquerda para a direita: Paulo Leminski, sobrinha de Mario Quintana, Mário Quintana, Alcides Buss e Bella Jozef. Imagem cedida pela Agência de Comunicação da UFSC (Agecom).

Figura 5. Gravação do documentário perdido com os poetas conferencistas. Da direita para a esquerda: Alcides Buss (de costas), Paulo Leminski, Mário Quintana, o jornalista Alfredo Bessow, Alice Ruiz, Renata Pallotini, C. Ronald, Gilberto Mendonça Telles, Raul Antelo e Inès Mafra. Inagem cedida pela Agência de Comunicação da UFSC (Agecom). 
A partir do exame desses documentos relativos às viagens "oficiais" de Paulo Leminski para Santa Catarina percebe-se que ele encontrava no estado um interlocutor privilegiado no autor de $O$ código das águas e As Annamárias, Lindolf Bell: tratava-se de um poeta com quem Leminski mantinha amizade e de quem era admirador, apesar de suas trajetórias diversas e mesmo opostas. Esta proximidade torna-se mais patente com a leitura de "Bellvindo, Lindolf", texto de Leminski inédito em livro, escrito especialmente para o $2^{\circ}$ Caderno do Correio de Notícias (PR) do dia 13 de setembro de 1985, menos de duas semanas depois da realização da III Bienal Nestlé de Literatura Brasileira em Floria nópolis. Texto cujo título já é uma homenagem, bem ao estilo de Leminski, ao "poeta mais bonito do Brasil" e que pode ser lido como uma espécie de carta aberta, uma vez que conta como e onde conheceu o cata rinense e discorre sobre suas afinidades e diferenças. Ao mesmo tempo, "Bellvindo, Lindolf" funcionava realmente como boas-vindas ao a migo, já que naquele mesmo dia o poeta lançava o seu Código das águas (1984) no Instituto Goethe de Curitiba. Reproduzimos o texto ao lado.

Portanto, com a diluição do credo concretista de Leminski nos idos de 85 , a beleza da poesia falada de Bell passa a ter lugar. Se as suas poéticas não podiam se

$13 / 09$

20 Caderno

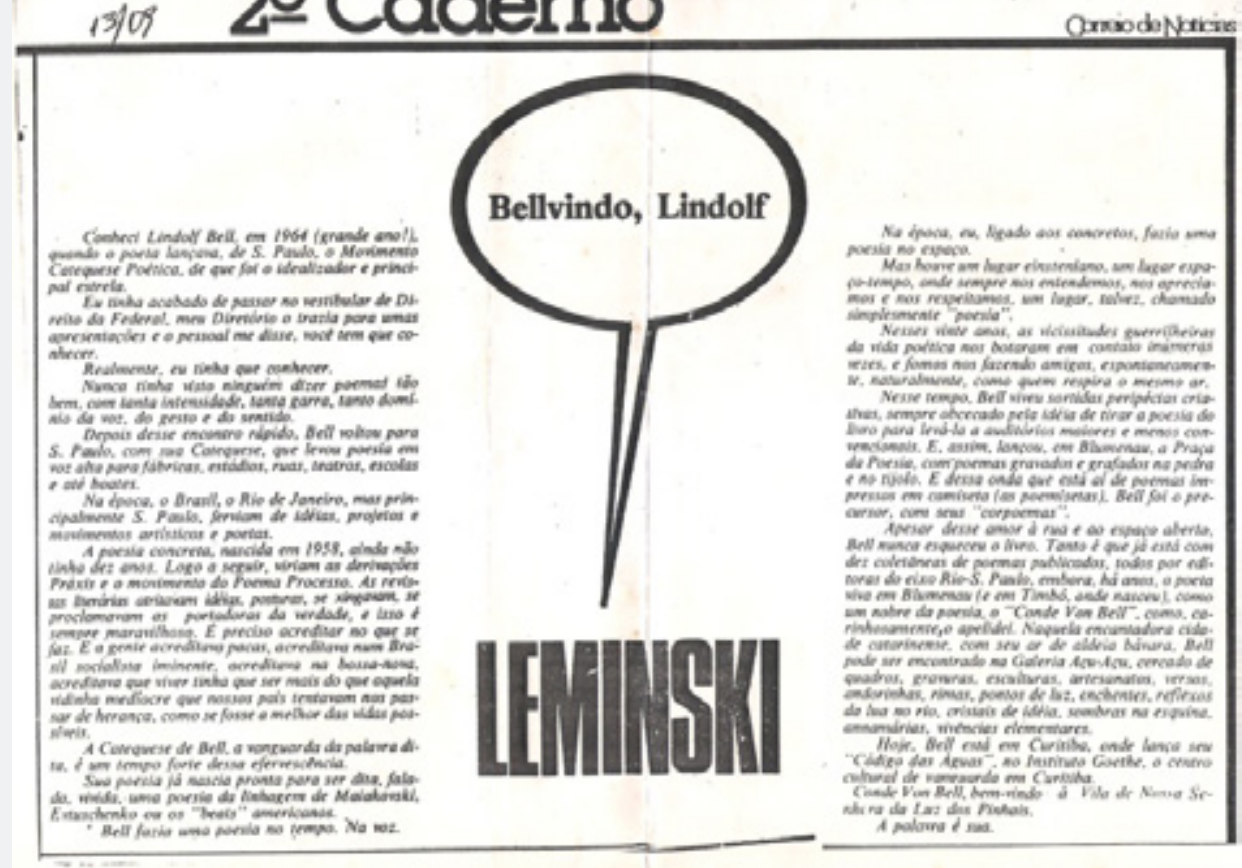

encontrar no espaço, se encontrariam no tempo, como afirma no texto o admirador do poeta de Timbó - admiração dirigida sobretudo a sua luta incansável por levar poesia às massas, algo que o próprio Leminski vinha fazendo principalmente como compositor. Conforme o início do texto, os poetas se conhecera m jovens, em 1964 em São Paulo, onde Bell viveu e cursou a Escola de Arte Dramática. Depois houve um novo encontro em Curitiba e, ao voltar para a capital paulista com a Catequese Poética - vista como "a vanguarda da palavra dita" -, "levou poesia em voz alta para fábricas, estádios, ruas,

EM TESE BELO HORIZONTE $\quad$ v. $26 \quad$ N. $3 \quad$ Set.-Dez. 2020 CLESAR; WOLF. Poesia esparsa, destino esparso: Leminski em Santa [...] $\quad$ P. 153-171

Teoria, Crítica Literária, outras Artes e Mídias 
teatros, escolas e até boates". Como observado acima, o texto pertence aos últimos anos de vida de Leminski, quando ele já se permite abrir o flanco para outras vertentes literárias, o que também permitiria que fizesse as pazes com o velho inimigo Dalton Trevisan, passando a olhá-lo de maneira surpreendentemente diferente no final, conforme se leria no jornal Nicolau, dirigido por Wilson Bueno: "Com a morte de Rosa e Clarice Lispector, Dalton faz, com certeza, a melhor prosa da ficção do Brasil, a mais ágil, mais malandra, mais louca" (LEMINSKI, 1990b, p. 10, grifo nosso). Com Lindolf Bell, passaria algo parecido: Leminski se permite abraçar uma poética bem distinta daquela "dos campos e espaços", em que a poesia se torna arte vestível através dos pioneiros "corpoemas" de Bell. Como registra no final do texto, se o poeta da intensidade vocal voltaria a viver na província natal, Timbó, tampouco deixaria de manter seu prestígio no chamado “eixo Rio-São Paulo”, uma vez que seus livros seguiam sendo publicados por editoras de lá. Ao mesmo tempo, lançava seu novo livro na sede paranaense do Instituto Goethe, "o centro cultural de vanguarda de Curitiba", como se lê no final do texto.

Assim, entre o afeto e o reconhecimento de Leminsk ao poeta-a migo nas boas-vindas a Curitiba, finalizemos este texto com a menção às artes vestíveis segundo o
“Conde Von Bell”. Dizia o autor de Distraídos venceremos em "Bellvindo, Lindolf": "Dessa onda que está aí de poemas impressos em camisetas (as poemisetas), Bell foi precursor com seus 'Corpoemas'”. Mas os "Corpoemas" não eram uma novidade na trajetória de Bell, que teve sua primeira edição ainda em 1973, com o deslocamento do poema de seu a mbiente convencional, o livro, passando a ser estampado em camisetas. Iniciativa esta em que inseria literalmente o corpo num projeto político de divulgação da poesia (no sentido de ir além do restrito campo intelectual) que era tributário de Lygia Clark e Hélio Oiticica e que possibilitava o trânsito da poesia por lugares e formas inesperadas. Segundo o próprio Bell, a ideia era possibilitar a leitura do corpo alheio, unindo a "magia do corpo" à do poema:

o poema na camiseta se multiplica infinitamente. O corpo torna-se condutor do poema ou de seus fragmentos. A fragmentação é característica de nossa civilização. As pessoas começarão a ler o poema impresso na roupa e, consequentemente, a ler o corpo alheio. O corpo torna-se, assim, parte integrante do poema, como este será parte integrante da paisagem diária. $\mathrm{O}$ poema poderá ser um instrumento de reconhecimento mútuo: estabelecer, para homem e palavra poética, uma plasticidade, alicerçada sobretudo na magia do corpo e na magia do próprio poema. (BELL, 1974, p. 222 apud TOMELIN, 2018, p. 11) 
Três anos depois do lançamento do livro de Bell em Curitiba, seria possível ver seus "Corpoemas" nos happenings que Leminski realizou para o Jornal da Vanguarda, da Rede Bandeirantes de Televisão. Era 1988 e lá estava ele na tela da tevê, em sua própria catequese poética para as massas, como que anuncia ndo a imensa receptividade que sua poesia teria no século vindouro em forma de livro. Mas, para além do meio livro, é sabido que sua poesia andarilha seguia igualmente o seu destino esparso, mas permanente, de mão em mão, em guardanapos, em papéis soltos, que tomava m ca minhos ao acaso e destinos imprevisíveis, da lata de lixo a uma gaveta onde repousa achado ou perdido. Este poema do corpo que, a final de contas, como em Lindolf Bell, só justificaria sua existência em relação com um outro, na forma do um que devém outro: devir menor que se desloca do livro em direção ao corpo, da revista ao papel solto, do espaço ao tempo, da letra à voz.

Na edição do dia 6 de julho de 1988, como colunista do Jornal da Vanguarda, apresentado por Dóris Giesse, Leminski veste uma sequência de camisetas esta mpadas com poesias, grafites, cartuns, e recita, como parte do happening, um poema de sua autoria e de data desconhecida, que não consta em Toda Poesia nem em qualquer outro meio impresso conhecido. Como tantos outros, este poema teria permanecido, efêmero, na oralidade, poesia nascida pra ser "dita, falada, vivida", como ele mesmo observara a respeito da poesia de Bell, (cujo sobrenome é já em si sonoro). Segue a transcrição do poema recitado na tevê:

Meu corpo é uma página,

eu visto palavras, frases, poemas poemas meus, teus, nossos.

Eu homem parede, homem grafite,

tatuagem provisória, o corpo como suporte do texto.

Por onde eu passo visto sentidos,

sílabas vibrando,

sinais da minha, da nossa passagem pelas ruas, pelo mundo.

Minha camisa é uma bandeira,

minhas ideias gritando como num outdoor,

me leia, me leia, me leia.

De modo que com "vestir a poesia" se propunha colocar em xeque, literalmente, os seus modos de circulação, multiplicar os seus percursos, provocar o debate sobre sua materialidade, observar como se comporta quando vestida por inúmeras pessoas em praças públicas, como fazia Bell, ou quando vestida por um poeta que se exibe para o público amplo da televisão, como fez Leminski. Levar ao extremo a difusão e o alcance da poesia, investir 
Figura 6. Leminski no Jornal da Vanguarda, na Rede Bandeirantes de Televisăo, em 1988. Disponive em: <htips./Www.youtube.com/

Figura 7. Leminski no Jornal da Vanguarda, na Rede Bandeirantes de Televisăo, em 1988, vestindo um poema de Caprichos e Relaxos (1983). Disponivel em: <https://www.youtube.

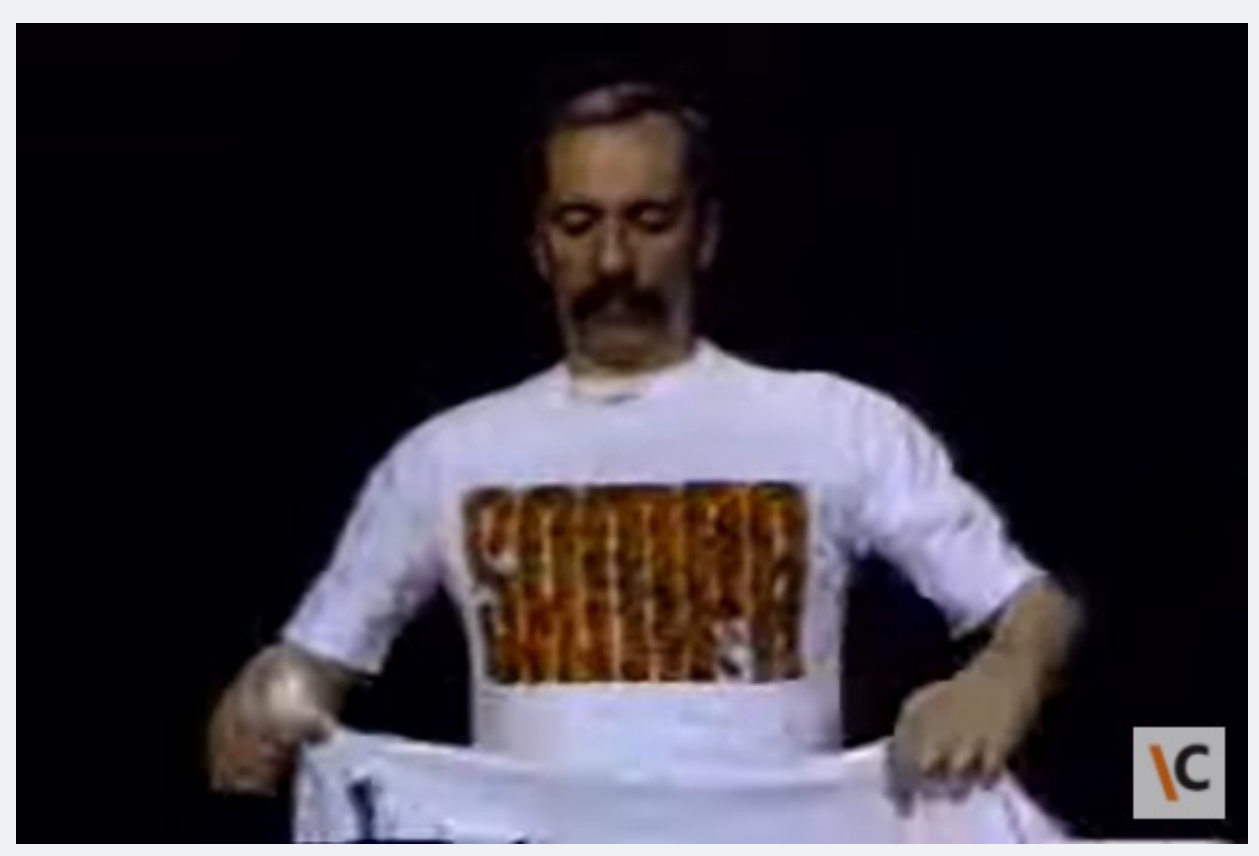

na sua disseminação multitudinária da poesia, na transgressão do seu lugar tradicional usa ndo o corpo como outdoor. Algo parecido ocorria com o conhecido hábito de Leminski de fazer a via crucis etílico-poética pelos bares de Curitiba, distribuindo poemas que irão tomar rumos imprevistos, distintos, singulares, como aconteceu com aqueles que entregou para o a migo e jornalista Martim Vaz. A história é contada pelo próprio destinatário desta poesia do acaso na coluna "Pamonha 77", de 31 de março de 1977, do Diário do Paraná, narrando uma visita à casa do poeta em Curitiba, conhecido ponto de encontro da rapaziada da cidade: "Cruzar o Leminski no Pilarzinho; na cruz do Pilarzinho. Ele que me presenteou - como só se faz a um irmão - com o poema do anjo. Me a marrei

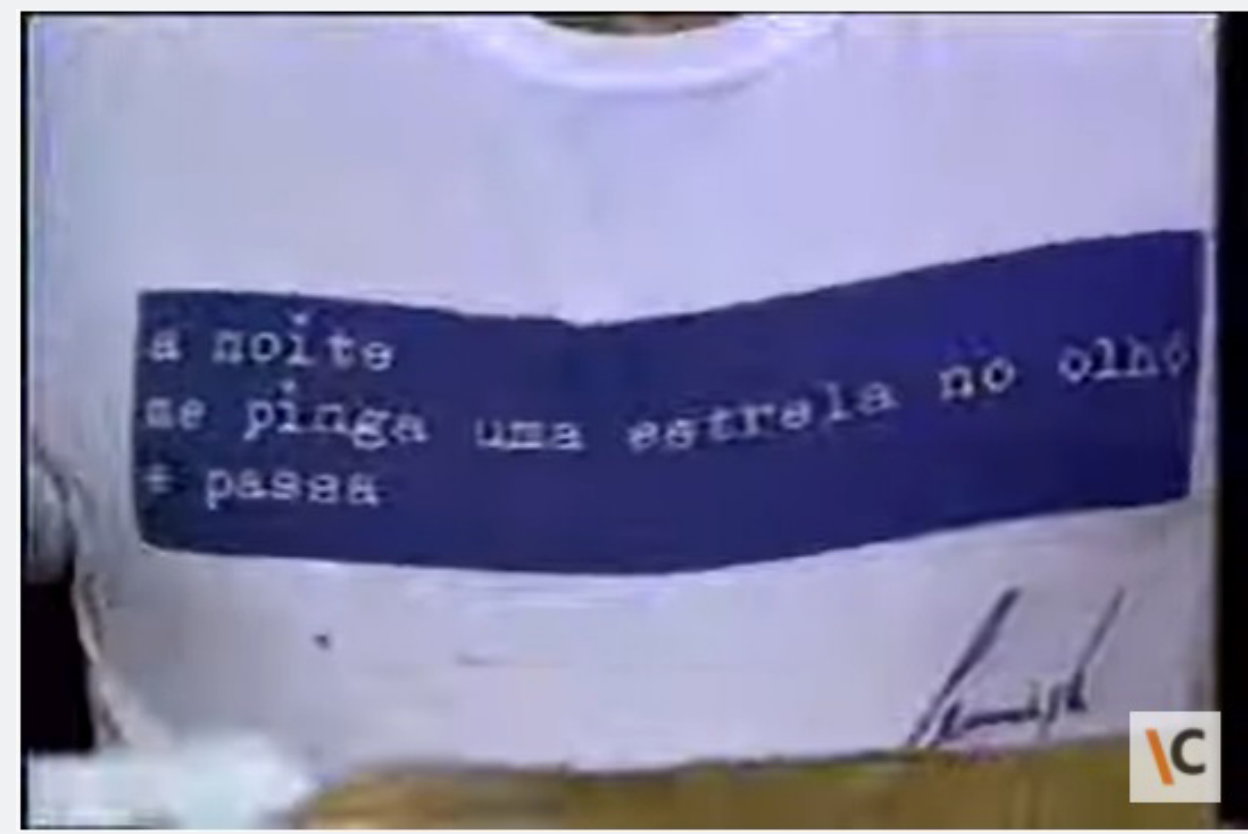
no poema do anjo". Particularmente safado e inventivo, na melhor tradição do poema-piada, trata-se de um breve diálogo, de um papo reto:

\section{o anjo}

disse à anja:

- vamos procurar o sexo dos anjos?

- é canja,

disse ela

tire a roupa

o resto a gente arranja 
Assim, entre camisetas e guardanapos, a poesia de Paulo Leminski ia ganhando corpo, a ponto de mais de duas décadas depois de sua morte seguir aprontando, ao transformar uma antologia poética de sua obra - Toda poesia, de 2013 (que está longe de ser "toda") - em novo e surpreendente best-seller póstumo. Como ele diria no final da vida a respeito de Dalton Trevisan - quem diria -, sua literatura foi e segue sendo para um vasto e renovado público leitor "a mais ágil, mais malandra, mais louca".

\section{BIBLIOGRAFIA}

BELL, Lindolf. Entrevista concedida à Maria Amélia

Melo. Tribuna da Imprensa, Rio de Janeiro, 14-15,

ago. 1976. Disponível em: <http://memoria.bn.br/

docreader/154083 03/24691 >. Acesso em: 18 jul. 2020.

Entrevista concedida à Tribuna da Imprensa. Tribuna da Imprensa, Rio de Janeiro, 5-6, set. 1976. Disponível em: <http://memoria.bn.br/DocReader/154083_03/24915>. Acesso em: 18 jul. 2020.

BERTOLINO, Pedro. Entrevista concedida à Maria Amélia Melo. Tribuna da Imprensa, Rio de Janeiro, 14-15, ago. 1976. Disponível em: < http://memoria.bn.br/ docreader/154083_03/24692>. Acesso em: 18 jul. 2020
BUSS, Alcides. Em nome da Poesia. Florianópolis: Caminho de Dentro, 2018

DELEUZE, Gilles; GUATTARI, Felix. Kafka: por uma literatura menor. Trad. Júlio Castañon Guimarães. Rio de Janeiro:

Imago, 1977.

FERRÓn, Fabio Maleronka; ARRUDA, Maria Firmino do Nascimento. Cultura e Política: a criação do Ministério da Cultura na redemocratização do Brasil. Tempo Social, São Paulo, v. 31, n. 1, p. 173-193, 17 abr. 2019. Disponível em: <http://www.revistas.usp.br/ts/article/ view/144335/152074>. Acesso em: 17 jul. 2020.

FLORES, João Aderson. Entrevista cedida à Tribuna da Imprensa (RJ). Tribuna da Imprensa, Rio de Janeiro, 14-15 ago. 1976. Suplemento da Tribuna. Disponível em:<http:// memoria.bn.br/DocReader/154083 03/24691 >. Acesso em: 28 set. 2020

FONSECA, Jeferson Rafael da. Nossa Senhora do Aterro: Florianópolis a partir das crônicas ligeiras de Beto Stodieck (1971-1980). 2008. 165 f. Dissertação (Mestrado) - Curso de História, Universidade Federal do Rio Grande do Sul, Porto Alegre, 2008. 
Fundação Nestlé Brasil. Nossa História. Disponível em: $<$ https://www.nestle.com.br/proposito/fundacao-nestlebrasil/nossa-historia>. Acesso em: 23 set. 2020.

HOLLANDA, Heloisa Buarque de. Impressões de Viagem: cpc, vanguarda e desbunde 1960/70. São Paulo: Brasiliense, 1980

KELLERMANN, Noemi. Blumenau em Cadernos no 11-12, p. 299-326. In: SCHVARTZ, Daiana. Elke Hering: Crítica, circuito e poética. 2013. 131f. Dissertação (mestrado) Artes Visuais, Universidade Estadual de Santa Catarina, Florianópolis, 2013.

Leminski na Vanguarda - Renato Barbieri - Ocupação Paulo Leminski (2009). In: Itaú Cultural. Plataforma Youtube. Disponível em: <https://www.youtube.com/ watch?v=ZE5YpiGwoTU> . Acesso em: 30 de set. 2020

LEMINSKI, Paulo. Bellvindo, Lindolf. Correio de Notícias, $2^{\circ}$ Caderno. Curitiba, 13.09.1985. 1990a.

Cruz e Sousa. In

Vida. Porto Alegre: Sulina,

Disparates do Duarte. Nicolau. ano I, n.4, Curitiba: Governo do Estado do Paraná, 1990b.
Entrevista concedida a Almir Feijó. Diário do Paraná Curitiba, 22, mar. 1977. Suplemento Anexo. Disponível em: <http://memoria.bn.br/docreader/761672/118612>. Acesso em: 18 jul. 2020

Entrevista concedida à Maria Amélia Melo. Tribuna da Imprensa, Rio de Janeiro, 14-15 ago. 1976. Suplemento da Tribuna. Disponível em: < http://memoria.bn.br/ docreader/154083_03/24692>. Acesso em: 18 jul. 2020.

Poema. Medusa: revista de poesia e arte. n.6 Curitiba, ago-set, 1999. p.10.

Toda Poesia. 2. Ed. São Paulo: Companhia das Letras, 2013.

BONVICINO, Régis (org.). Uma carta uma brasa através: cartas a Régis Bonvicino. São Paulo: Iluminuras, 1992.

MALAGOLI DA SILVA, Héverton. Modernismo e história da literatura na década de 1950 em Santa Catarina. Santa

Catarina em História, Florianópolis, v. 1, n. 2, p. 37-44, 2007. Disponível em: http://www.nexos.ufsc.br/index.php/ sceh/article/viewFile/49/110. Acesso em:

01 jun. 2020 
PELLEGRINI, Domingos. Minhas Lembranças de Leminski São Paulo: Geração Editorial, 2014.

Presença de Paulo e Alice. Jornal de Santa Catarina

Blumenau, 08.10.1976.

Prossegue Semana da Poesia. Jornal de Santa Catarina. Blumenau, 30.07.1976.

SACHET, Celestino. Panorama da Literatura em Santa Catarina. Travessia, Florianópolis, n.3, p. 108-113, 1981.

SCHVARTZ. Daiana. Elke Hering: Crítica, circuito e poética. 2013. 131f. Dissertação (mestrado) - Artes Visuais,

Universidade Estadual de Santa Catarina, Florianópolis, 2013.

TELES, Gilberto Mendonça. Entrevista concedida à Maria Amélia Melo. Tribuna da Imprensa, Rio de Janeiro, 1415, ago. 1976. Disponível em: <http://memoria.bn.br/ docreader/154083 03/24691 >. Acesso em: 18 jul. 2020.

TOMELIN, Rafael. Verso veste pele: sobre a materialidade dos "Corpoemas" de Lindolf Bell. 2018. 86 f. Monografia (Especialização) - Curso de Letras Português, Universidade Federal de Santa Catarina, Florianópolis, 2018.
VAZ, Martins. O anjo. Diário do Paraná, Curitiba, 31, mar 1977. Pamonha 77. Disponível em: <http://memoria.bn.br/ docreader/761672/118907>. Acesso em: 18 jul. 2020. 